\title{
THE EFFECT OF RAPID AND GRADUAL WEIGHT LOSS ON SOME HEMATOLOGICAL PARAMETERS IN TRAINED WRESTLERS
}

\author{
Javad Ghaemi ${ }^{1}$, Amir Rashidlamir ${ }^{2}$, Seyyed Reza Attarzadeh Hosseini ${ }^{1}$, Gholam Rasul Mohammad Rahimi ${ }^{1}$ \\ ${ }^{1}$ Ferdowsi University of Mashhad, Mashhad, Iran \\ ${ }^{2}$ University of Mashhad, Mashhad, Iran
}

\begin{abstract}
Introduction: Weight loss is a common issue among athletes, especially wrestlers. It is important that the various methods of weight loss be studied relative to the effect on athletic performance as well as the athletes' immune systems. The purpose of this study was to compare the effects of rapid and gradual weight loss methods on white blood cells in trained wrestlers.
\end{abstract}

Materials and Methods: 22 trained wrestlers (age 20-25years) volunteered to participate in the present research and were randomly assigned into one of two groups: Group 1 used rapid weight loss in a $48 \mathrm{~h}$ period, and Group 2 used gradual weight loss over a 12 day period. All subjects were asked to reduce 4 percent of their weight. Before and after weight loss intervention, blood sampling was performed, as well as the physical performance tests (simulated wrestling competition).

Results: White blood cells increased significantly in both groups $(p<0.05)$. The amount of this increase was out of normal range in the rapid group, but remained within the normal range in the gradual group. Neutrophils increased significantly while lymphocytes decreased significantly in the rapid group $(p<0.05)$.

Conclusion: Comparing these two weight loss protocols showed that the rapid weight loss method had more deleterious effects on the immune systems of wrestlers than a gradual weight loss plan.

Key Words: weight loss, white blood cell, Neutrophil, Lymphocyte, wrestler

\section{INTRODUCTION}

There is great interest in the need to improve community health through exercise. A topic attracting researchers is an understanding of the mechanisms that improve health or cause damage to the immune system during exercise $(9,15)$. In many cases, high-intensity exercise may induce significant changes in leukocyte distribution and function, causing a temporary impairment of immune function during the recovery period (4). Although most immune cells increase during exercise, during recovery after intense exercise, a suppressed immune system can result, and the risk of infection increases $(20,21)$. In addition to the exercise intensity, repeated bouts of exercise with just a several hour break may also cause changes in the immune system through a nervous-hormonal-stress response. This may increase the period of risk during the recovery period $(3,6,14,15)$. Heavy exercise causes a temporary suppression of the cellular and hormonal immune system; it causes a reduction in peripheral blood neutrophils, killer cells (natural killer cell) and lymphocytes, and it may take two weeks to recover $(3,22)$. Hematologic indices in sports medicine are vital and necessary. These indices are used for the diagnosis, management and prevention of these deleterious effects from training (25). The effect of exercise on the hemostasis system depends on some parameters such as intensity, duration and the initial state (10). In longterm physical activity, the redistribution of body fluids occurs in order to maintain efficiency and is important in order to maintain sport skills, not only during practice and the race but also for maintaining good health (2). Many studies have been done on the effect of exercise on hematological indices that suggest different results (11). Wu et al (24) observed an increase in white blood cells after a 24-hour ultra-marathon race. Weight loss may cause a reduction in resistance to infection, such as an upper respiratory tract infection, besides a drop in athletic performance $(16,22)$. In addition to the type and intensity of exercise, dehydration and weight loss, done repeatedly during a season of hard exercise can have adverse effects on the immune system and the ability of athletes (14). Weight loss may cause a lack of fitness and the ability to participate in the competition; the internal organs of the body including the kidneys, liver and heart are exposed to damage, so weight loss should be based on scientific principles, diet and proper training (17). Many studies have been done on the impact of rapid weight loss techniques on physiological and psychological factors in weight category sports, with little difference between the results indicating the negative effects of rapid weight loss on the above factors (7).

There has been a proposal for a new method of weight reduction in wrestlers using a gradual approach (17). The aim of this research is compare the effects of acute and gradual weight loss methods on some hematological parameters. 


\section{ATERIALS AND METHODS}

This study is a semi-experimental study. From trained wrestlers living in Khorasan-Razavi province, 22 wrestlers with a mean age of $22.5 \pm 2.3$ and $\mathrm{BMI}$ of $23.9 \pm 2$ volunteered to participate in the study. They were randomly assigned into two weight loss groups. Group 1 used the acute (rapid weight loss) and Group 2 used the gradual weight loss method. Blood samples were collected in three phases: before weight loss (A phase), 14 hours after the weight loss period (B phase) and after the last test ( $C$ phase). This timeline is shown in table 1. Percent of changes in plasma volume were calculated according to the Dill and Costill formula (5). Prior to weight loss and $14 \mathrm{~h}$ after the weight loss, body composition was analyzed using bioelectric impedance analysis. Aerobic capacity and anaerobic power were measured by the Bruce treadmill and Wingate (arms and legs) tests respectively. All subjects were required to lose $4 \%$ of their body weight. Participants in rapid group reduced their weight during 48 hours via traditional methods (severe diet, fluid restriction and using sauna). Participants in gradual group were monitored and evaluated to determine the amount and type of food intake. Then, they were asked to reduce their weight according to the Rashidlamir's method during 12 days and are shown in table 2 . In this method, there are three four-day phases. In the first three days of each phase nutrition is decrease and on the day there is a return to the diet to the previous phase. In the first phase, the subjects decreased their food intake by $10 \%$ for three days (lunch and dinner) and then they returned to their usual eating habits on the fourth day (daily dietary habit before the protocol). In the second period, first they decreased their food intake by $20 \%$ for three days, then they returned to $10 \%$ on the fourth day. In the third phase, first they decreased their food intake by $30 \%$ for three days and then they returned to $20 \%$ on the fourth day. There was no limitation on drinking water and no decrease in breakfast, but the subjects avoided fat in all meals.

Table 1: Guidelines to evaluate the performance of wrestlers

\begin{tabular}{|c|c|c|c|c|c|c|c|c|c|}
\hline \multicolumn{2}{|c|}{ Pre-test } & $\begin{array}{c}4 \% \\
\text { weight }\end{array}$ & \multicolumn{2}{|c|}{ Post-test 1} & $\begin{array}{l}\text { Rest } \\
(20\end{array}$ & $\begin{array}{l}\text { Post- } \\
\text { test } 2\end{array}$ & $\begin{array}{l}\text { Rest } \\
(20\end{array}$ & \multicolumn{2}{|c|}{ Post-test 3} \\
\hline Morning & Evening & & Morning & Evening & & & & Evening & immediately \\
\hline $\begin{array}{c}\text { Body } \\
\text { composition }\end{array}$ & $\begin{array}{c}\text { Arm } \\
\text { Wingate }\end{array}$ & & $\begin{array}{c}\text { Body } \\
\text { composition }\end{array}$ & $\begin{array}{c}\text { Arm } \\
\text { Wingate }\end{array}$ & & Wingate & & Arm & \\
\hline Blood & $\begin{array}{c}\text { Leg } \\
\text { Wingate }\end{array}$ & & Blood & $\begin{array}{c}\text { Leg } \\
\text { Wingate }\end{array}$ & & Leg & & Wingate & $\begin{array}{l}\text { Blood } \\
\text { sample }\end{array}$ \\
\hline $\begin{array}{c}\text { sample } \\
\text { (A phase) }\end{array}$ & $\begin{array}{c}\text { Bruce } \\
\text { Test }\end{array}$ & & $\begin{array}{l}\text { sample } \\
\text { (B phase) }\end{array}$ & $\begin{array}{c}\text { Bruce } \\
\text { Test }\end{array}$ & & wingate & & $\begin{array}{c}\text { Leg } \\
\text { Wingate }\end{array}$ & (c pnase) \\
\hline
\end{tabular}

\begin{tabular}{|l|c|c|c|c|c|c|c|c|c|c|c|c|c|}
\hline \multicolumn{10}{|c|}{ Table 2: A decrease in food for wrestlers to lose weight } \\
\hline & $\begin{array}{c}1^{\text {st }} \\
\text { day }\end{array}$ & $\begin{array}{c}2^{\text {nd }} \\
\text { day }\end{array}$ & $\begin{array}{c}3^{\text {rd }} \\
\text { day }\end{array}$ & $\begin{array}{c}4^{\text {th }} \\
\text { day }\end{array}$ & $\begin{array}{c}5^{\text {th }} \\
\text { day }\end{array}$ & $\begin{array}{c}6^{\text {th }} \\
\text { day }\end{array}$ & $\begin{array}{c}7^{\text {th }} \\
\text { day }\end{array}$ & $\begin{array}{c}8^{\text {th }} \\
\text { day }\end{array}$ & $\begin{array}{c}9^{\text {th }} \\
\text { day }\end{array}$ & $\begin{array}{c}10^{\text {th }} \\
\text { day }\end{array}$ & $\begin{array}{c}11^{\text {th }} \\
\text { day }\end{array}$ & $\begin{array}{c}12^{\text {th }} \\
\text { day }\end{array}$ \\
\hline $\begin{array}{l}\text { Reduction } \\
\text { in lunch }\end{array}$ & $10 \%$ & $10 \%$ & $10 \%$ & $\begin{array}{c}\text { eating } \\
\text { as usual }\end{array}$ & $20 \%$ & $20 \%$ & $20 \%$ & $\begin{array}{c}\text { eating } \\
\text { as usual }\end{array}$ & $30 \%$ & $30 \%$ & $30 \%$ & $20 \%$ \\
\hline $\begin{array}{l}\text { Reduction } \\
\text { in dinner }\end{array}$ & $10 \%$ & $10 \%$ & $10 \%$ & $\begin{array}{c}\text { eating } \\
\text { as usual }\end{array}$ & $20 \%$ & $20 \%$ & $20 \%$ & $\begin{array}{c}\text { eating } \\
\text { as usual }\end{array}$ & $30 \%$ & $30 \%$ & $30 \%$ & $20 \%$ \\
\hline
\end{tabular}

\section{PARTICIPANTS}

The population of this study was the trained wrestlers with a history of at least 5 years of continuous practice. In addition they often have participated in national competitions and all of them had at least a provincial or national championship rank.

\section{STATISTICAL ANALYSIS}

The data were analyzed using Kolmogorov-Smirnov, one-way ANOVA and repeated measures tests, at the minimum significant level of $p<0 / 05$ using SPSS software(version 16).

\section{RESULTS}

The hematological test results are shown in table 3. The average of white blood cells count in both acute and gradual groups in phase B (14 hours after weight loss) did not increase significantly. However, in the acute group in phase B we observed a $4.7 \%$ increase in white blood cells as compared to the phase A (before weight loss), however the gradual group in phase B (14 hours after the weight loss) showed a reduction of $5.4 \%$ in white blood 
ills as compared to phase A (before weight loss). White blood cells in both acute and gradual groups in phase

(after the final stage of the athletic performance tests) were significantly increased ( $p \leq 0.05)$. This increase in white blood cells in the acute group (after the last performance test) was 53\% (out of the normal range) as compared to phase A (before weight loss); on the other hand the increase of white blood cells in gradual group in phase $\mathrm{C}$ (after the last performance test) was $42 \%$ (in the normal range) as compared to phase A (before weight loss).

The average of neutrophils in both acute and gradual groups in phase $B$ did not significantly increase, but in acute group, it increased by $1 \%$ in phase B, as compared with phase A; although in gradual group a reduction of $4 \%$ was observe in phase $B$ as compared to the $A$ phase. . However in the acute group in phase $C$ we observed a significant increase $(p \leq 0.05)$; but in the gradual group in phase $C$ they did not significantly increase.

The average lymphocytes in both groups in phase $B$, did not show a significant decrease. However, there was a $1.7 \%$ decrease in the acute group in phase $B$ as compared to phase $A$. Additionally, in the gradual group in phase $\mathrm{B}$, there was an increase of $4.7 \%$, as compared to phase $\mathrm{A}$, but in the acute group in phase $\mathrm{C}$ there was a significant decrease $(p<0.05)$; however, in the gradual group there were no significant decrease.

Table3: the average of WBC, significance level and changes in different phases

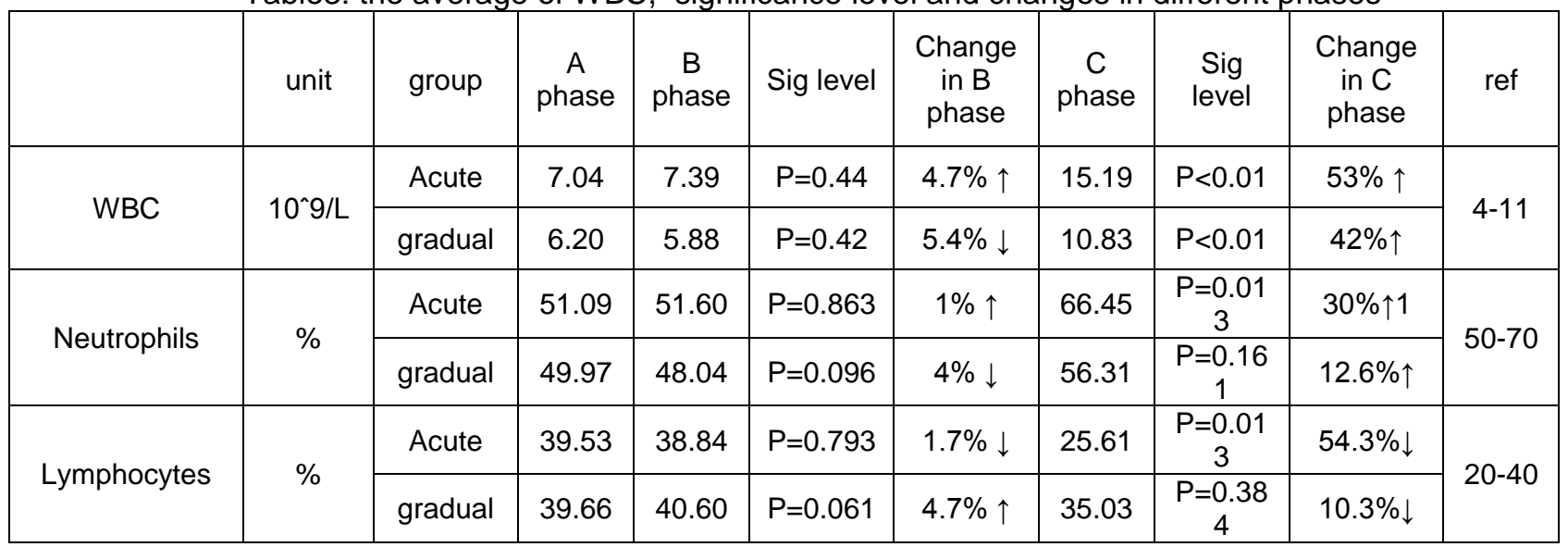

\section{DISCUSSION}

The results showed that the average number of white blood cells increased in both the acute and gradual groups' weight loss groups. This increase was found to be $53 \%$ (out of the normal range) and $42 \%$ (out of the normal range) in the acute and gradual groups respectively. These changes in both groups were statistically significant $(p \leq 0.05)$. The possible mechanism explaining this phenomenon could be that acute weight loss is a severe physiological stress that can be associated with disorders in immune variables and individuals who are more prone to specific diseases such as upper respiratory tract infections. This issue for competitive athletes may be of particular importance. That is because they must be in the optimal physiological condition to do their best in performance $(14,22)$.

The increase in leukocytosis in this research was similar to other studies $(8,12,24)$, that may also be due to neutrocytosis that is affected by changes in the levels of catecholamines and cortisol (24). According to the role of neutrophil phagocytosis during inflammation and their increase, this explanation is plausible because intense exercise can cause muscle damage, and as a result of this injury, white blood cells levels are increased. It could be that some factors such as an increase in the activity of the sympathetic nervous system, increased cardiac output and changes in endothelial cells of capillaries are effective in releasing cells attached to the walls of the capillaries into the bloodstream (23). Neutrophils are also increased in both acute and gradual groups; it was statistically significant in the acute group $(p \leq 0.05)$. Although lymphocyte levels decreased in both acute and gradual group, there was a significant reduction in the acute group $(p \leq 0.05)$.

The increase in neutrophils has been also observed in other studies of the impact of intense exercise $(13,19)$. The increase in the number of white blood cells in this study was associated with an increased numbers of neutrophils. Other studies have also shown that the increase in neutrophils during exercise is greater than the increase in total 
Irite blood cell (6). In other studies, lymphocyte changes were reported to be similar to changes in white b

cells and neutrophils. That was not found in the present study our findings $(18,20)$. Although it is generally believed that the lymphocyte count becomes elevated immediately after exercise and remains elevated for 24 hours, it decreases and reaches the lower limit of normal (6). A reduction in the number of lymphocytes is very important, as athletes are susceptible to viral infections during weight loss. In the acute group, the increase in white blood cell count may be related to stress, weight loss, physical activity, or the concentration of cells due to dehydration, (and not a reduction in the number of cells). Differences between our findings and other studies could be due to differences in the diet, the weight loss method and length of the study. Additionally, the increase in the white blood cell count can be due to increased catecholamines, particularly adrenaline and an increase in cortisol during exercise $(1,6)$. In some studies, the difference between weight loss, exercise and physical activity are not seen, so the theoretical effects of catecholamines and cortisol is considered as one of the strong factors in this regard $(6,13)$. This increase can be sustained for minutes or hours after exercise and gradually return to normal levels $(6,22)$. Imai et. al reported similar changes in two groups (weight loss and no weight loss) in judo athletes (13). Increases in WBC count and neutrophils were observed in rapid weight loss group. Rapid weight loss, as compared to gradual weight loss, has a more damaging effect on the immune system and may lead to severe repression of the immune system following this method. Therefore, we may conclude that acute weight loss can seriously threaten the wrestlers' health.

\section{PRACTICAL ADVICE FOR COACHES AND WRESTLERS}

Therefore, coaches and wrestlers are recommended to avoid acute weight loss methods and use the recommended method from this research a gradual method. With the gradual weight loss method, wrestlers can preserve their health status, successfully lose their weight, preserve their sporting performance and gain better results.

\section{REFERENCES}

1. AK., B. (2006). "Acute exercise and innate immune function. Immune Function in Sport and Exercise. 1st ed. Churchill Livingstone: Philadelphia." 67-89.

2. Amir-Sasan R and S.-S. V. (2002). "Effect of intense aerobic activity on red blood cell indices of male athletes [Article in Persian]." Motion 9: 89-99.

3. Bishop, N. C. (2006). "Exercise and infection risk." Immune Function in Sport and Exercise. Advances in Sport and Exercise Science Series: 1-14.

4. Braun, W. A. and S. P. von Duvillard (2004). "Influence of carbohydrate delivery on the immune response during exercise and recovery from exercise." Nutrition 20(7): 645-650.

5. Dill, D. and D. L. Costill (1974). "Calculation of percentage changes in volumes of blood, plasma, and red cells in dehydration." Journal of Applied Physiology 37(2): 247-248.

6. Eliakim, A., B. Wolach, E. Kodesh, R. Gavrieli, J. Radnay, T. Ben-Tovim, Y. Yarom and B. Falk (1997). "Cellular and humoral immune response to exercise among gymnasts and untrained girls." International journal of sports medicine 18(03): 208-212.

7. Fogelholm, G. M., R. Koskinen, J. Laakso, T. Rankinen and I. Ruokonen (1993). "Gradual and rapid weight loss: effects on nutrition and performance in male athletes." Medicine and science in sports and exercise 25(3): 371-377.

8. Ghanbari Niaki, A., S. Tayebi, F. Ghorbanalizadeh Ghaziani and J. Hakimi (2005). "Effect of a single Session of Weight-Circuit Exercise on Hematological changes of Physical education Students." Journal of sports sciences 1(2): 77-88.

9. Gleeson, M. (2007). "Immune function in sport and exercise." Journal of applied physiology 103(2): 693699.

10. Habibian, M., J. Moosavi, F. Tojari and R. Moosavi-Gilani (2010). "Comparison the effects of one session aerobic exercise and resistance training on some of the coagulation markers of healthy young women." Zahedan Journal of Research in Medical Sciences 12(4): 33-37.

11. Hemat Far, A. (2001). "Eight weeks of endurance running increasingly on selected blood factors and maximum oxygen consumption." Olympics 8(16): 59-70.

12. Hulmi, J. J., T. Myllymäki, M. Tenhumäki, N. Mutanen, R. Puurtinen, G. Paulsen and A. Mero (2010). "Effects of resistance exercise and protein ingestion on blood leukocytes and platelets in young and older men." European journal of applied physiology 109(2): 343-353. 
13. Imai, T., S. Seki, H. Dobashi, T. Ohkawa, Y. Habu and H. Hiraide (2002). "Effect of weight loss on T-d receptor-mediated T-cell function in elite athletes." Medicine and science in sports and exercise 34(2) 245-250.

14. Nielsen, H., N. Secher, M. Kappel, B. Hanel and B. Pedersen (1996). "Lymphocyte, NK and LAK cell responses to maximal exercise." International journal of sports medicine 17(01): 60-65.

15. Nieman, D. C. and B. K. Pedersen (1999). "Exercise and immune function." Sports Medicine 27(2): 73-80.

16. Oppliger, R. A., G. L. Landry, S. W. Foster and A. C. Lambrecht (1993). "Bulimic behaviors among interscholastic wrestlers: a statewide survey." Pediatrics 91(4): 826-831.

17. Rashid Lamir, A. (2009). "The comparison of acute and gradual weight loss methods in well-trained wrestlers." World journal of sport sciences 2.

18. Roberts, W. O. (1998). "Certifying wrestlers' minimum weight: a new requirement." The Physician and sportsmedicine 26(10): 79-81.

19. Rowbottom, D. G., D. Keast and A. R. Morton (1996). "The emerging role of glutamine as an indicator of exercise stress and overtraining." Sports Medicine 21(2): 80-97.

20. Shephard, R. J. (2003). "Adhesion molecules, catecholamines and leucocyte redistribution during and following exercise." Sports medicine 33(4): 261-284.

21. Smith, L. L. (2003). "Overtraining, excessive exercise, and altered immunity." Sports Medicine 33(5): 347364.

22. Steen, S. N. and K. D. Brownell (1990). "Patterns of weight loss and regain in wrestlers: has the tradition changed?" Medicine and science in sports and exercise 22(6): 762-768.

23. Tayebi, S., A. H. AGHA, K. Kiadaliri and G. F. GHORBANALIZADEH (2011). "Assessment of CBC in physical activity and sport: a brief review." BLOOD (KHOON).

24. Wu, H.-J., K.-T. Chen, B.-W. Shee, H.-C. Chang, Y.-J. Huang and R.-S. Yang (2004). "Effects of $24 \mathrm{~h}$ ultra-marathon on biochemical and hematological parameters." World Journal of Gastroenterology 10(18): 2711-2714.

25. Younesian, A., M. Mohammadion, N. Rahnama and T. Cable (2004). "Haemathology of professional soccer players before and after 90 min match." Cell Mol Biol Lett 9(2): 133-136. 